УДК 332.142

\title{
ТЕОРЕТИЧЕСКИЕ АСПЕКТЫ КОНКУРЕНТОСПОСОБНОСТИ ГОРОДА
}

\author{
С.А.БУНЬКО \\ аспирант кафедры экономической теории и логистики \\ Брестского государственного технического университета, г. Брест
}

Аннотация

В статье исследуются особенности городов как субъектов конкуренции. Сделан вывод о необходимости повышения внимания к управлению конкурентоспособностью таких территориальных образований как города. Это обусловлено тем, что все уровни конкурентоспособности национальной экономики взаимосвязаны. Повышение конкурентоспособности городов как центров инновационной активности, благоприятной среды для формирования и развития креативного сектора экономики создаёт импульсы для повышения конкурентоспособности всех уровней как территориальных, так и производственных экономических систем.

Abstract

The article features considess the features of the cities as subjects of competition investigated. The conclusion is drawn to need of increase of attention to management of competitiveness of such territorial areas as cities. It is caused by that all levels of competitiveness of national economy are interconnected. Increase of competitiveness of cities as centers of innovative activity, favorable environment for formation and development of creative sector of economy creates impulses for increase of competitiveness of all levels of both territorial, and production economic systems.

\section{ВВЕДЕНИЕ}

Понятие конкурентоспособности в настоящее время является предметом исследовательского интереса во многих сферах и применяется по отношению к самым разным объектам. В отношении территорий понятие конкурентоспособности стало применяться в западной экономической науке во второй половине ХХ в. Некоторые исследователи, в частности П.Кругман, критически относятся к применению данного понятия по отношению к странам, регионам, городам, считая, что конкурентоспособность - «атрибут компаний» [1] .

Несмотря на это, оценка конкурентоспособности стран, регионов, городов приобретает всё большую популярность. На наш взгляд, усиление интереса к данной тематике произошло с введением понятия квазикорпорации, которое применил А.Г. Гранберг по отношению к регионам [2]. Тем самым учёный подчеркнул уникальность каждого уровня экономики страны, рассматриваемой в качестве сложной многоуровневой системы. Это проявляется в том, что каждый уровень можно рассматривать как проекцию: а) более высокого уровня; б) более низкого уровня. Это обосновывает возможности заимствования традиционных методов исследования макро- или мезоуровня для микроуровня, и наоборот.

Управление конкурентоспособностью городов является одним из наименее разработанных направлений в региональной экономике. В Республике Беларусь, как и на всём постсоветском пространстве, управление городами как объектами сложной социально-экономической природы не получало должных теоретических основ. Целью данного исследования является уточнение: сущности конкурентоспособности города, для чего необходимо исследовать подходы к пониманию конкуренции; территориальной конкурентоспособности; роли города в формировании конкурентоспособности на всех уровнях; состава субъектов, объектов и предметов конкуренции.

\section{РЕЗУЛЬТАТЫ И ИХ ОБСУЖДЕНИЕ}

Одной из причин расхождений во взглядах на природу конкурентоспособности является неоднозначная трактовка сущности самой конкуренции, к пониманию которой в настоящее время сложилось три подхода.

Во-первых, поведенческий подход, в котором конкуренция рассматривается как рыночный механизм свободного соперничества агентов в целях достижения лучшего, по сравнению с другими участниками рынка, результата.

Во-вторых, структурный подход, в котором акцент переносится с борьбы рыночных агентов между собой на структуру рынка, определяющего характер их конкурентного противостояния. При таком подходе конкуренция «из деятельного феномена, по сути, превращается в структурный феномен, привлекающий внимание учёных не своей внутренней механикой, а ролью в установлении рыночных пропорций и микроэкономическими последствиями» [3].

В-третьих, функциональный подход, который смещает рассмотрение экономической сущности конкуренции в сторону изучения ее роли в экономическом развитии.

При рассмотрении сущности конкурентоспособности целесообразно базироваться на поведенческом подходе, поскольку важным является не то, какова интенсивность конкуренции, а то, каким образом участники рынка могут управлять интенсивностью собственных конкурентных действий, наращивать конкурентные преимущества, побеждать соперников в условиях неопределённости рынков.

В рамках поведенческого подхода единой трактовки данного понятия также не выработано. Среди учёных нет согласованности в следующих вопросах: к каким объектам можно применять понятие конкурентоспособности; существует ли его единое определение? Положив в основу эти два ключевых момента, А.И.Коваленко описал существую- 
щие подходы и обосновал наибольшую приемлемость объективистского подхода. В его основе лежит признание единого определения конкурентоспособности, которое сохраняется в отношении любых объектов, но при этом множество объектов строго ограничено и трактуется как способность субъекта конкуренции в определённой сфере деятельности совершать конкурентные действия сравнительно лучше конкурирующих субъектов [4]. Такой вывод опирается на мнение, что «теоретический отрыв конкурентоспособности от конкурентных действий чреват выхолащиванием самого понятия конкурентоспособности», превращением в «синонимы эффективности, прибыльности, интенсивности упоминания на рынке - в зависимости от объекта рассмотрения» [5].

Объективистский подход ставит задачу определения сферы деятельности, в которой конкурируют города. Конкурентоспособность города является малоизученным понятием. Тем не менее, сформировалось мнение, что это понятие является близким по своей природе к конкурентоспособности региона, страны. Обзор источников, посвящённых исследованию сущности конкурентоспособности территориальных социально-экономических систем (ТСЭС), таких как страна, регион, город, позволил выделить шесть основных подходов к её трактовке.

Во-первых, подход, основанный на понимании конкурентоспособности ТСЭС как набора определённых свойств, обеспечивающих конкурентные преимущества по сравнению с другими территориями (М.И.Гельвановский, Г.А.Унтура, Р.А.Фатхутдинов и др). Такая трактовка является неполной, так как отражает лишь предпосылки к способности совершать конкурентные действия.

Во-вторых, подход, опирающийся не столько на наличие конкурентных преимуществ, сколько на способность эффективно их использовать (Н.Я.Калюжнова, В.Н.Чайников, Л.С.Шеховцева и др). Рассматривает эффективность использования ресурсов в сравнении с конкурентами, но упускает из виду конкуренцию на рынках.

В-третьих, подход, основанный на способности продуцировать конкурентные преимущества (Н.Е.Костылева, Е.О.Миргородская, М.Портер и др). Исходной посылкой является динамичность конкурентоспособности, что является несомненным достоинством подхода.

В-четвёртых, подход, связывающий конкурентоспособность ТСЭС со способностью выдерживать конкуренцию на товарных рынках (В.В.Меркушев, В.В.Печаткин, С.В.Дохолян и др.). В данной трактовке конкурентоспособность сводится к конкурентоспособности предприятий, расположенных на его территории. Это определяет её ограниченность, так как достижение конкурентоспособности предприятий не всегда свидетельствует о конкурентоспособности ТСЭС в целом.

В-пятых, подход, основанный на способности создавать условия для привлечения на территорию внешних инвесторов, туристов, потенциальных жителей (Б.М.Гринчель, Е.И.Мазилкина, Т.В.Ускова и др.). Характерен для территориального маркетинга и рассматривает конкурентоспособность ТСЭС только с точки целевых потребителей территории как товара.

В-шестых, подход, определяющий конкурентоспособность ТСЭС как способность обеспечивать устойчивое социально-экономическое развитие (Г.Я.Белякова, А.А.Мельдаханов, Л.Н.Чайникова и др.). Такое понимание заложено в документах Европейской комиссии и связывается, в первую очередь, с устойчивым ростом уровня жизни и как можно меньшим уровнем вынужденной безработицы. В основе подхода лежит признание особенностью территорий невозможность ухода с рынка, даже в том случае, если она оказывается неконкурентоспособной. То есть, в таком случае происходит ухудшение благосостояния населения, ужесточение ведения бизнеса, сокращения занятости, поэтому понятие конкурентоспособности города приближается к понятию устойчивого развития. Несмотря на то, что подход в настоящее время является самым распространённым, по нашему мнению, он не соответствует положениям объективистского подхода. В нём отражены глобальные цели управления конкурентоспособностью, но не её сущность.

Таким образом, в настоящее время не сформировано подхода, в котором бы учитывались все аспекты территориальной конкуренции. Кроме того, дополнительного прояснения требует вопрос взаимосвязи эффективности и конкурентоспособности, поскольку единого мнения на этот счет не существует.

Такие исследователи как О.А.Сухарев, А.А.Воронов, И.А.Заярная считают, что условием конкурентоспособности является более эффективное использование ресурсов относительно по сравнению с конкурентами.

По мнению Р.А. Фатхутдинова, конкурентоспособность является «непременным условием повышения эффективности народно-хозяйственного комплекса и каждой организации в отдельности» [6]. Логика подхода такова: неконкурентный товар покупатели не будут покупать, изготовитель не окупит свои затраты и не получит прибыли для эффективного воспроизводства.

Некоторое объяснение такой полярности взглядов на связь конкурентоспособности и эффективности можно дать исходя из концепции конкуренции, предложенной С.Хантом. Учёный определяет конкуренцию как постоянную борьбу между рыночными агентами за сравнительные преимущества в отношении ресурсов, которые ведут к достижению преимущественного положения на рынке и, как следствие, к более высокому финансовому результату [7]. Из концепции С.Ханта следует вывод, что конкурентоспособность имеет двойственную природу: с одной, стороны, является источником эффективности в виде конкурентных преимуществ, с другой - достигнутая эффективность использования ресурсов ведёт к лучшей конкурентной позиции на рынке, то есть повышению конкурентоспособности на рынке товаров.

Ещё одним важным моментом является необходимость преодоления статичности объективистского подхода. В связи с этим, необходимо обратить внимание на такую составляющую конкурентоспособности как возможность адаптации субъекта к изменяющимся условиям конкуренции [8]. Под возможностью адаптации, по нашему мнению, следует понимать способность субъекта конкуренции разрабатывать успешную конкурентную стратегию и своевременно вносить коррективы, исходя из сложившейся на рынке конкурентной ситуации. 
Уточнение сущности конкурентоспособности города требует также определения его места и роли в системе территориальной конкурентоспособности. То есть, необходимо выявить взаимосвязь элементов конкурентоспособности, формирующихся на различных уровнях, а также взаимовлияние элементов конкурентоспособности производственных и территориальных экономических систем.

Подавляющая часть исследований в области конкурентоспособности посвящена изучению конкуренции на макро- и микроуровнях, где участниками конкуренции являются страны и фирмы-производители. В последнее время достаточно много внимания уделяется мезоуровню конкуренции - на уровне отрасли и региона. Города же по-прежнему остаются упущенным звеном в цепочке конкурентоспособности. Их развитие рассматривается в большей степени с точки зрения пространственного и инфраструктурного развития. В западной экономической науке напротив, именно развитию городов, повышению их конкурентоспособности придаётся особое значение. Мнения об особой значимости городов придерживается и Д.П.Фролов: «несмотря на серию «прорывных» теоретических исследований Дж.Хендерсона, М.Фуджита, Э.Венеэйблса и др., наблюдается примат регионов над городами, хотя урбанизация не менее значима, чем регионализация» [9].

Конкурентоспособность страны, региона, города по мнению большинства исследователей, во многом определяется конкурентоспособностью предприятий, кластеров, расположенных на их территории. Это означает зависимость конкурентоспособности территории от возможностей конкретного производителя выпускать товар, ценовые и качественные характеристики которого определяют его успех на внешнем рынке.

Действительно, при прочих равных условиях, фирмы конкурируют за спрос посредством цены и качества товаров. Но при базировании в различных городах, регионах или странах, у фирм могут появляться дополнительные конкурентные преимущества на основе стоимости факторов производства, преимуществ инфраструктуры, квалифицированной рабочей силы, активности бизнес-среды и других факторов. Таким образом, существует и обратная связь. Для производства фирмой конкурентоспособного товара нужны определённые условия, которые можно охарактеризовать как конкурентоспособность города, региона, на территории которых они функционируют. В то же время конкурентоспособность городов, регионов во многом определяется имиджем страны, её вовлечённостью в международные процессы, институциональными и многими другими условиями. Из этого следует вывод, что конкурентоспособность низшего уровня является частью конкурентоспособности более высокого уровня, существует взаимовлияние производственных и территориальных экономических систем всех уровней. Роль каждого уровня определяется присущими ему особенностями.

Согласно самому распространённому подходу, опирающемуся на численность и род занятий населения, городом является крупный населённый пункт, большая часть населения которого занята несельскохозяйственным трудом.

При этом абсолютное большинство исследователей наиболее характерной чертой городов считают концентрацию на сравнительно ограниченной территории практически всех видов деятельности, которая предопределяет особые функции города (его доминирование), вытекающие из его центральных характеристик: агломерация, близость, лёгкость взаимодействия, быстрая циркуляция информации и т.д. [10].

Влияние развития городов на общенациональное развитие, с учётом их особых функций, рассматривается в теориях «полюсов роста» (Ф. Перру, Ж.Б. Будвиля), «центр-периферия» (Дж. Фридмана), пространственной «диффузии инноваций» (Т. Хагерстранда, П. Хаггета) и др.

Ф.Перру предложил в условиях ограниченности ресурсов использовать принцип сосредоточения усилий в «привилегированных точках», которые он назвал «полюсами роста» и рассматривал в их качестве лидирующих отраслей [11]. Ж.Б. Будвиль показал, что функции «полюсов роста» могут выполнять не только отрасли, но также города и регионы за счет концентрации на своей территории производств, определяющих НТП и создающих устойчивый спрос на факторы производства. Под полюсом роста учёный понимал «набор развивающихся и расширяющихся отраслей, размещенных в урбанизированной зоне и способных вызывать дальнейшее развитие экономической деятельности во всей зоне своего влияния» [12].

А.Г. Гранберг также связывал «полюса роста» с городами и трактовал их как «географическую агломерацию экономической активности» [13].

Такая роль городов предопределяется привлекательностью для инноваций, формирующих исходное ядро всех изменений (технологических, социальных, институциональных и т.д.) на основе высокой плотности значимой информации и отношений взаимодействия между отдельными предприятиями.

Кроме того, в настоящее время в качестве приоритетного направления всё чаще рассматривается развитие креативного сектора экономики, благоприятной средой для развития которого являются именно города в силу концентрации на своей территории необходимых ресурсов.

Из этого следует вывод, что глобальной целью повышения конкурентоспособности города будет не только повышение качества жизни его населения, но и увеличение вклада в развитие региона и страны в целом.

Для уточнения сущности конкурентоспособности города также необходимо более чётко определить субъекты конкуренции, объекты и предметы конкуренции.

Под субъектами конкуренции будем понимать участников процесса рыночных отношений, стремящихся удовлетворить свои экономические интересы в соперничестве с другими. Для выделения субъектов конкуренции необходимо рассмотреть типы взаимодействия конкуренции: вертикальный и горизонтальный.

Вертикальный тип предполагает соперничество между вышестоящими, в частности региональными, органами управления и городской администрацией за объём предоставляемых полномочий и распределение финансовых ресурсов. 
Горизонтальный тип - соперничество между городами. При этом целесообразно опираться на классификацию конкуренции, предложенную Е.Г.Анимицей [14]:

- между близко расположенными городами, объединёнными в некую целостность;

- между большими городами в пределах крупного экономического района;

- между крупнейшими городами разных экономических районов;

- с зарубежными городами.

На наш взгляд, интересной является также теория Т.Неидомюсля и М.Йонассона [15], согласно которой при выделении приоритетных конкурентов городу следует принимать во внимание:

- расположение городов на «шкале влияния», положение на которой будет зависеть от величины капитала, которое город привлекает по сравнению с другими регионами;

- расстояние между городами, измеряемое не только дальностью, но и временем, затрачиваемым на преодоление данного расстояния.

Это позволяет сделать вывод, что определение городов в качестве приоритетных конкурентов и, в дальнейшем, выбор стратегии повышения конкурентоспособности в значительной степени будет зависеть от численности населения города, его исторической функциональности и экономико-географического положения.

Подходы к выделению объектов и предметов межтерриториальной конкуренции является ещё одним дискуссионным вопросом. Причиной, на наш взгляд, является смешение подходов к территории как субъекту и объекту конкуренции и игнорирование момента «этапности» протекания конкуренции: сначала на рынке ресурсов, а затем на товарном рынке.

Под объектами рыночной конкуренции будем понимать его составляющие, на которые направлены действия субъектов конкуренции как на рынке ресурсов, так и на товарном рынке. Следовательно, к объектам конкуренции можно отнести спрос (потребителей), и предложение (владельцев ресурсов).

Некоторые исследователи считают, что такие субъекты как территории, обладая определенными товарами, в частности, сырьевыми ресурсами, передают функции производителя отдельным предприятиям и не выступают субъектами рыночных отношений. То есть, не являются субъектами конкуренции на рынке спроса, а лишь создают предпосылки проявления, развития и поддержания конкурентных преимуществ того или иного производителя. Такие субъекты как города, регионы, страны могут выступать субъектами конкуренции только на рынке предложения «за привлечение на свою территорию как факторных, так и нефакторных товаров» [16].

Опирается такой вывод на суждения Л.Берга, Е.Брауна и Дж. Меера, которые считали, что «города и регионы все более становятся ключевыми акторами экономического развития, выдвигая себя на роль предпринимателей. Их руководители хотят вовлечь свой регион в конкурентную борьбу, привлекая новые виды деятельности в форме инвестиций и различного рода визитеров. Они также стремятся создать лучшие условия для местных фирм, которые и являются участниками конкурентной борьбы» [17].

По нашему мнению, город, выдвигая себя на роль предпринимателя, может участвовать в формировании спроса на продукцию местных производителей как на внутреннем, так и на внешнем рынке. Это возможно за счёт позиционирования города, создания и продвижения бренда города, участия в выставках и ярмарках, создания собственных торгово-информационных центров за рубежом, проведения «Дней культуры» города в других регионах и странах и других мероприятий. Таким образом, город, являясь заинтересованным в повышении конкурентоспособности фирм, расположенных на его территории и вносящих вклад в его конкурентоспособность, принимает на себя часть маркетинговых функций.

Исходя из этого, на рынке предложения в качестве объектов конкуренции можно выделить следующие группы: собственники организаций, инвесторы, малый бизнес, вышестоящие властные структуры, квалифицированные специалисты, население. Предметами конкуренции могут являться:

- научно-производственные ресурсы (сохранение существующих и размещение новых организаций всех видов деятельности, научных, инновационных центров и т.д.);

- финансовые ресурсы (инвестиции в производственную, научную и образовательную сферу, инфраструктуру, развитие туризма и т.д.; гранты, кредиты);

- человеческие ресурсы (сохранение и привлечение населения на постоянное место жительства, в том числе квалифицированных специалистов; привлечение маятниковых мигрантов и т.д.).

На рынке спроса в качестве объектов конкуренции можно выделить следующие группы потребителей: внутренние, региональные, инорегиональные, зарубежные. Предметами же конкуренции на данном рынке могут являться:

- товары в классическом понимании (материальные) и нематериальные товары (технологии, инновационные разработки и т.д.);

- услуги (транспортные, образовательные, медицинские, туристические, логистические, развлекательные и т.д.);

- события (спортивные, культурные, научные, ярмарочно-выставочные) и др. 


\section{ВЫВОДЫ}

На основе проведённых исследований представляется возможным сформулировать уточнённое определение конкурентоспособности города с учётом его особенностей.

По мнению автора, конкурентоспособность города - способность на основе эффективного использования существующих и вновь создаваемых конкурентных преимуществ, быстрой адаптации к изменяющимся рыночным условиям, создавать лучшие условия для привлечения необходимых ресурсов и успешного соперничества товаропроизводителей - резидентов города на рынках товаров и услуг, по сравнению с другими территориальными образованиями с целью постоянного повышения качества жизни населения города и увеличения вклада города в развитие региональной и национальной экономики.

Исследование особенностей городов показывает, что повышение их конкурентоспособности, во-первых, как центров инновационной активности, привлекающих предприятия инновационных индустрий и инновационные интеллектуальные ресурсы, и, во-вторых, как благоприятной среды для формирования и развития креативного сектора экономики, создаёт импульсы для повышения конкурентоспособности всех уровней - как территориальных, так и производственных экономических систем. Это подтверждает необходимость повышения внимания к управлению конкурентоспособностью таких территориальных образований как города.

\section{ЛИТЕРАТУРА}

1.Николаева, Н.А. Конкурентоспособность города: взгляд зарубежных учёных / Н.А.Николаева // Маркетинг в России и за рубежом. - 2001.-№6.- с. 69-76. - С. 69.

2.Гранберг, А.Г. Основы региональной экономики. М. : Государственный университет ВШЭ, 2006. - 495 с. - С. 154.

3.Рубин, Ю.Б. Дискуссионные вопросы современной конкуренции // Современная конкуренция, 2010. - №3 (21).c.38-67. - С. 40.

4.Коваленко, А.И. Теоретические и методологические аспекты использования концепции «конкурентоспособности» в научных исследованиях // Современная конкуренция. - 2013. - №6 (42). - с.65-79. - С. 69-71.

5. Рубин, Ю.Б. Дискуссионные вопросы современной конкуренции // Современная конкуренция, 2010. - №3 (21).c.38-67. - С. 60 .

6. Фатхутдинов, Р.А. Управление конкурентоспособностью организации: учеб./Р.А.Фатхутдинов. 3-е изд., перераб. И доп.. - М.: Маркет ДС, 2008. - 432 с. - С. 39.

7.Хандамова, Э.Ф Экономическая природа конкуренции и конкурентоспособности предприятия (корпорации) [Электронный ресурс]. - 2012 - Режим доступа: http://ej.kubagro.ru/2012/08/pdf/43.pdf . - Дата доступа: 25.01.2015

8. Адаева, Т. Ю. Организационные факторы и резервы повышения конкурентоспособности предприятия / Т. Ю. Адаева. - Пенза: Изд-во Пензенского гос. ун-та, 2009. - 27 с. - С. 26.

9. Фролов, Д. П. Маркетинговая парадигма регионального развития: монография / Д. П. Фролов. - 2-е изд., доп. - Волгоград : Изд-во ВолГУ, 2013. - 157 с. - С. 88.

10. Занадворов, В.С., Ильина, И.П. Теория экономики города: Учеб. пособие. - М.: Изд. дом ВШЭ, $1999 .-$ 195 c. - C. 88 .

11. Андрианов, В.Д. Эволюция основных концепций регулирования экономики: от теории меркантилизма до теории саморегуляции / В.Д. Андрианов. - М.: Изд-во «Экономика», 2008. - 326 с. - С. 61.

C. 87.

12. Гранберг, А.Г. Основы региональной экономики. М. : Государственный университет ВШЭ, 2006. - 495 с. -

13. Гранберг, А.Г. Основы региональной экономики. М. : Государственный университет ВШЭ, 2006. - 495 с. C. 87.

14. Анимица Е.Г. Градоведение : Учебник / Е. Г. Анимица, Н. Ю. Власова. - Екатеринбург : Изд-во Урал.гос. экон. ун-та, 1998. - 309 с. - С. 41.

15. Неидомюсль, М. Йонассон, К теории территориального маркетинга // Маркетинг и маркетинговые исследования. - № 2 (104). - 2013. - с.150-158. - С. 152-155.

16. В.А.Логинова Проблемы конкурентоспособности в современной экономике // Проблемы современной экономики. [Электронный ресурс]. - 2009. - Режим доступа: http://www.m-economy.ru/art.php?nArtId=2404. - Дата доступа: 25.01.2015

17. В.А.Логинова Проблемы конкурентоспособности в современной экономике // Проблемы современной экономики. [Электронный ресурс]. - 2009. - Режим доступа: http://www.m-economy.ru/art.php?nArtId=2404. - Дата доступа: 25.01.2015

Статья поступила в редакциию 17 июля 2015 года. 